\title{
Gastric submucosal bleeding tumor. Do you think about glomus tumor of stomach?
}

\begin{abstract}
Glomus tumor is a rare mesenchyme tumor of the gastrointestinal tract, especially of stomach. We describe unusual presentation of gastric Glomus tumor of 76-year-old patient who presented with upper gastrointestinal bleeding. Subsequent investigation showed tumor of $3 \mathrm{~cm}$ at the posterior wall of the stomach. A wedge resection of the tumor was performed using laparoscopic staplers. The histological examination and immunohistochemical stains confirmed diagnosis of gastric Glomus tumor. We discuss the management before operation, the problems of diagnosis and surgical treatment of the patient with unusual location and presentation of the lesion.
\end{abstract}

Keywords: glomus tumor, stomach, sub mucosal lesion, upper gastrointestinal bleeding, laparoscopic wedge resection, gastrointestinal tract, staplers, glomus cells, gastroscopy, GIST, immunohistochemical
Volume 3 Issue 3 - 2015

\author{
Vyacheslav Bard,' Ludmila Fridel,' Hanoch \\ Kashtan' \\ 'Department of General Surgery, Tel Aviv University, Israe \\ ${ }^{2}$ Department of Pathology, Tel Aviv University, Israel
}

Correspondence: Vyacheslav Bard, Department of Genera Surgery, Rabin Medical Center, Campus Beilinson, Tel Aviv University, Beilinson Hospital, Surgery B, Jabotinsky str. 39 Petach-Tiqwa, 49100, Israel, Tel 972-3-9376203, Fax 972-3937625I,Email slavab@clalit.org.il

Received: October 24, 2015 | Published: December 07, 2015

\section{Introduction}

Glomus tumor (GT) is a rare, benign smooth body-like cell made up of normal Glomus cells. Glomus body, neuromyoarterialglomus, is an arterio-venous shunt that is responsible for regulation of skin temperature. It is a rare neoplasm representing $2 \%$ of all soft tissue tumors. It is located usually in areas of rich skin flesh glomus (the subungual regions of digits or the deep dermis of the palm, wrist, forearm and foot). Particularly rare, but it can occur anywhere including gastrointestinal tract, nerves, respiratory tract.

\section{Case report}

A 76year old man was admitted due to upper gastrointestinal bleeding. He was hemodynamically stable. Physical examination was unremarkable except for melena on rectal examination. Nasogastric tube showed clear gastric content. There was no history of recent abdominal pain, weight lost or vomiting. On admission hemoglobin level was $8.9 \mathrm{~g} / \mathrm{dl}$. All other blood tests including coagulation profile were normal. After initial resuscitation, he underwent urgent Gastroscopy in which a sub mucosal $3 \mathrm{~cm}$ ulcerated mass was identified at the greater curvature without evidence of active bleeding. Bleeding ceased spontaneously. Further evaluation was performed. Endoscopic ultra sound showed a $3 \mathrm{~cm}$ mixed echogenicity mass arising from the sub mucosa without lymphadenopathy. Biopsies were not taken. An abdominal computer tomography confirmed the diagnosis of a $3 \mathrm{~cm}$ sub mucosal lesion with peripheral enhancement after injection of contrast material. PET CT showed a pathological uptake of FDG in the gastric tumor only (Figure 1) and a preoperative diagnosis of GIST were made.

Under general anesthesia a laparoscopic exploration was performed. A $3 \mathrm{~cm}$ tumor was found at the posterior wall of the stomach (Figure 2). There were no other pathological findings during the exploration of the abdomen cavity. A wedge resection of the tumor was performed using laparoscopic staplers. The patient had uneventful recovering period and was discharged 5 days after surgery. On slides taken from lesion showed the round cells with small uniform nuclei, without nuclear pleomorphic and no mitotic figures. The distribution of round glomus cells around the open vascular lumen is a key to the pathology diagnosis. The lesion was positive for alpha-smooth muscle Actine (alpha SMA), Calponin and negative for CD-34, C-KIT and CK MNF116. The proliferating marker showed very low mitotic rate, less than one per $50 \mathrm{HPF}$. The histological examination and immunohistochemical stains confirmed diagnosis of gastric glomus tumor (Figure 3). The surgical resection margins were free of tumor.

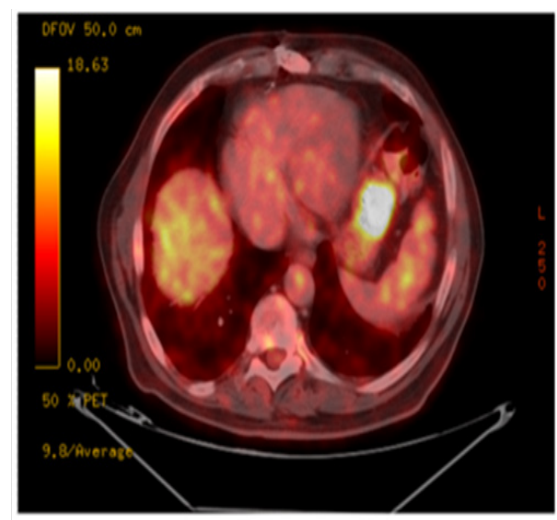

Figure I PET CT showed a pathological uptake of FDG in the gastric tumor.

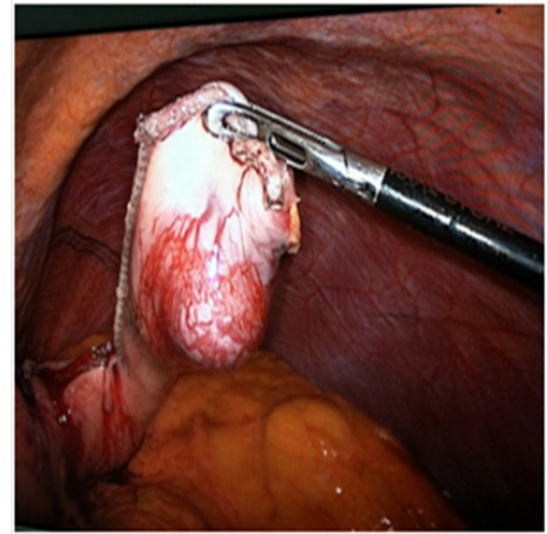

Figure $2 \mathrm{~A} 3 \mathrm{~cm}$ tumor was found at the posterior wall of the stomach. 


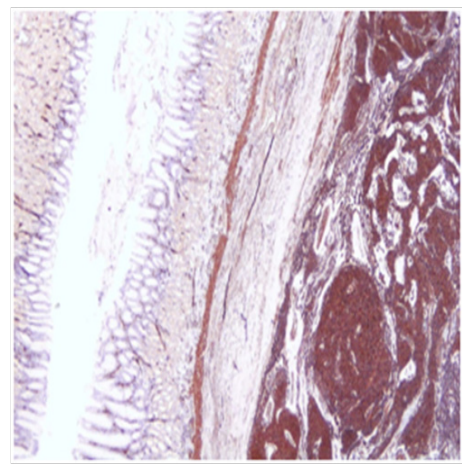

Figure 3 The histological examination and immunohistochemical stains of gastric glomus tumor.

\section{Discussion}

Glomus tumor was first described by Barre et al. ${ }^{1}$ They described the classic location at the subungual region of a digit. Later it was found that it may occur anywhere in the body, including skin, soft tissue, nerves, nasal cavity, trachea, liver and stomach. ${ }^{2}$ GT of stomach was first described by Talijeva and since then, about 200cases have been published. The incidence of GT is less common than that of gastrointestinal tumors (GIST), with only 1 in 100cases of GIST being gastric GT. Glomus tumor of the stomach is arising in the intramuscular layer. It usually present as a single solitary sub mucosal nodule of stomach. The most common presentation of GT is upper gastrointestinal bleeding. Preoperative differential diagnosis is difficult and includes all kinds of gastric mesenchyme tumors. GT of the stomach is rare finding, but it is the most frequent intraperitoneal glomus tumors. ${ }^{3}$ It arises in the intramuscular layer and occurs as a unitary submucosal lesion sometimes with obvious ulceration in the greater curvature. ${ }^{2-5} \mathrm{GT}$ of stomach generally is a benign tumor although it can be malignant and have the potential to metastasize. ${ }^{6,7}$ GTs usually occur in the fifth, sixth decade of life. The diameter of gastric GT is very variable; from $0.8 \mathrm{~cm}$ to $21 \mathrm{~cm} .{ }^{6}$ The preoperative diagnosis of GT is not easy. It is very important to note that imaging techniques fail to differentiate GT from other stromal or mesenchymal tumor, such as neuroendocrine tumors, GIST, Schwannoma and mainly vascular tumor such as hemangioma may show a similar pattern. ${ }^{8,9}$ There is no need to do endoscopic biopsy of intramural lesions due to its ineffectiveness especially when it is removable. The endoscopic ultrasound shows heterogeneous tumors between the sub mucosal and muscular propria layer which may be confused with GIST or leomyosarcoma. ${ }^{10,11}$

The most common symptom of GT is gastrointestinal bleeding as we observed in our patient. A full pre-operative evaluation led to a diagnosis of GIST. An accurate diagnosis was made only by a histological examination of the resected specimen. Even GT is usually benign, malignant behavior cannot be excluded. So, operative resection is one of the methods to reach right diagnosis. Wedge resection with negative margins should be treatment of choice for these patients. Histologically, GT of our patient had low risk of malignancy and macroscopically had about $2 \mathrm{~cm}$ in diameter. As published previously the classification criterion for malignant GT: deep location, size more than $2 \mathrm{~cm}$, presence of atypical mitotic figure; combination of moderate to high nuclear grade and mitotic activity (5mitoses/50 high power fields). ${ }^{12}$ There are no guidelines for follow up of patients who underwent resection of gastric GT. Recurrent GT is rare and occurs usually the site previous resection. Therefore, it is recommended to perform endoscopy annually. ${ }^{6}$

\section{Conclusion}

GT of the stomach is a rarely found benign mesenchyme tumor. Usually it is impossible to make a preoperative diagnosis. The only one diagnostic method is histological and immunohistochemical analysis. GT is usually benign, but malignant behavior cannot be excluded. So, there is indication for resection of tumor with negative margins.

\section{Acknowledgements}

None.

\section{Conflict of interest}

The author declares no conflict of interest.

\section{References}

1. Barre JA, Masson P. Etude anatocliniqui de certain estumeurssous unguealesdouloureuses (Tumeurs du glomusneuromyo-arterial des extremities). Bulletin de la Societe Francaise de Dermatologie et de Syphiligraphie. 1924;31:148.

2. Cha SH, Cho SB, Kim YW, et al. Helical CT appearance of glomus tumor of the stomach. Eur Radiol. 2000;10(4):671-673.

3. de Bruin AF, Verhoef C, den Bakker MA, et al. Glomus tumor of the mesentery with atypical feathers:a case report. Int J Surg Pathol. 2008;16(4):440-442.

4. Kim JK, Won JH, Cho YK, et al. Glomus tumor of the stomach: CT findings. Abdom Imaging. 2001;26(3):303-305.

5. Park SH, Han JK, Kim TK, et al. Unusual gastric tumors: radiologicpathologic correlation. RadioGraphics. 1999;19(6):1435-1446.

6. Tavusbay C, Genç H, Haciyanli M, et al. Glomus tumor of the stomach:a rare cause of upper gastrointestinal bleeding. Ulus Travma Acil Cerrahi Derg. 2009;15(1):85-87.

7. Apatenko AK, Smoliannikov AA. Malignant glomus tumor of the stomach. Arkh Patol. 1975;37(6):29-36.

8. Xu XD, Lu XH, Ye GX, et al. Immunohistochemical analysis and biological behavior of gastric glomus tumors: a case report and review of the literature. J Intern Med Res. 2010;38(4):539-1546.

9. Haque S, Modlin IM, West AB. Multiple glomus tumors of the stomach with intravascular spread. Am J Surg Pathol. 1992;16(3):291-299.

10. Huang CC, Yu FJ, Jan CM, et al. Gastric glomus tumor: a case report and review of the literature. Kaohsiung J Medical Science. 2010;26(6):321326.

11. Shah P, Gao F, Edmundowicz SA, et al. Predicting malignant potential of gastrointestinal stromal tumors using endoscopic ultrasound. Digestive Disease and Science. 2009;54(6):1265-1269.

12. Folpe AL, Glomus T. World Health Organization Classification of Tumours: Pathology and Genetics of Tumours of Soft Tissue and Bone. Lyon, France: IARC Press; 2002. p. 136-137. 